\title{
Emission Characteristics of Major Atmospheric Pollutants in Changchun City
}

\author{
Ju Wang ${ }^{1,}$, Yilian Zhao ${ }^{2}$, Kexin Xue ${ }^{1}$, Chunsheng Fang ${ }^{1}$ \\ ${ }^{1}$ College of New Energy and Environment, Jilin University, Changchun, China \\ ${ }^{2}$ College of Water Conservancy and Hydropower Engineering, Sichuan Agricultural University, Ya'an, China
}

Email address:

wangju@jlu.edu.cn (Ju Wang)

${ }^{*}$ Corresponding author

\section{To cite this article:}

Ju Wang, Yilian Zhao, Kexin Xue, Chunsheng Fang. Emission Characteristics of Major Atmospheric Pollutants in Changchun City. International Journal of Environmental Monitoring and Analysis. Vol. 8, No. 5, 2020, pp. 155-160. doi: 10.11648/j.ijema.20200805.14

Received: July 15, 2020; Accepted: September 8, 2020; Published: September 28, 2020

\begin{abstract}
Based on the technical guide for the preparation of air pollutant emission inventory, this paper makes a statistical analysis of the basic data of air pollution related to the Changchun, and according to the relevant literatures, establishes a list of the main air pollutant emissions from the Changchun 2016 air pollution emission sources (including fine particles, sulfur dioxide and nitrogen oxides). Then the uncertainty analysis is made by Monte Carlo method, and the countermeasures of Changchun air pollution control are put forward. The results showed that the total emission of $\mathrm{PM}_{2.5}$ in Changchun in 2016 was 70986.45t, and the emissions from the main sources are fixed combustion source, mobile source, process source, biomass burning source and dust source respectively. According to the analysis, we know that coal-based energy consumption structure not only contributes significantly to the emission of one fine particulate matter, but also emits a large number of two fine particulate precursor materials, such as sulfur dioxide, nitrogen oxides. The total sulfur dioxide emission in Changchun in 2016 is 52183.55t, and the total NOx emission is 13.15 million tons. The uncertainty analysis of the Monte Carlo method shows that the uncertainty range of the emission inventory is small and the estimation results are quite credible.
\end{abstract}

Keywords: Emission Inventory, Fine Particulate Matter, Sulfur Dioxide, Nitrogen Oxides

\section{Introduction}

In recent years, the air characteristics in Changchun have changed from the traditional soot-type pollution to the "compound" pollution. The pollution effect of $\mathrm{PM}_{2.5}$ is more than the traditional air pollutant due to its long transmission distance and longer stay time, which has become the primary index to characterize the urban air pollution [1]. Nitrogen oxides emissions seriously endanger human lung health, especially for children. And sulfur dioxide pollution will harm the health of human respiratory system, cause social and economic loss, which seriously affect the development of national economy and people's normal life [2]. It is of great significance to establish the air pollutant emission inventory, to study the spatial and temporal distribution and degree of air pollution in the region, to simulate the atmospheric environmental quality in the region, and to provide reference for the future development of air pollution control direction and atmospheric planning and management regulations [3].

Recently, the establishment of air pollutant emission inventory in China has been carried out successively, and the emission inventory of air pollutants has been set up at various scales. At the national scale, Tian Hozong and Wang Litao respectively established the National NOx emission inventory and Co emission inventory $[4,5]$; On the regional scale, Zheng Junyu set up the 2006 air pollutant emission inventory of the pearl river delta, and studied the spatial distribution of air pollutant emissions in the pearl river delta [6]; On the urban scale, Zhaobin and Ye Xianman set up the 2003 air pollutant emission inventory of Tianjin and the 2010 air pollutant emission inventory of Hangzhou city which provide a basis for the study of atmospheric governance in the region [7].

In today's increasingly serious air pollution, fine emission inventories can be more effective in identifying the source of emissions, and play an important role in the system to control emission reduction measures. In this paper, by constructing 
Changchun 2016 fine particulate matter, sulfur dioxide and nitrogen oxide source emissions inventory, lay the foundation for the future Changchun air pollution prevention and research work [8].

\section{Principle and Method}

In the process of establishing a fine particulate source emission inventory, based on the relevant contents of the preparation technology guide for the primary emission inventory of fine particulate matter in the air (for trial implementation), referring to the Changchun Statistical Yearbook (2016) and the Changchun Energy balance table, combining the basic statistic data of the relevant departments and the related literatures, the paper analyses the activity level data, emission factor and pollution control measures corresponding to the dust removal efficiency of the fixed combustion source and process source, biomass combustion source, mobile source and of the dust source, and finally atmospheric fine particulate matter source emissions inventory of Changchun in 2016 [9].

Fixed combustion source estimation process of various types of fuel consumption comes from the Changchun 2016 Energy balance table in the relevant data conversion, referring technology Guide to the fixed combustion source in accordance with the four classification, combined with the literature study according to the three classification of the production coefficient and four-class classification of the removal efficiency of the calculation, Finally, the $\mathrm{PM}_{2.5}$ emissions from the stationary combustion source are obtained.

The product classification and output of the process source is from the Statistical Yearbook and Energy balance sheet data analysis and collation, and the emission factor refers to Guide data, $\mathrm{PM}_{2.5}$ emissions estimation process in the dust removal efficiency.

The mobile sources are divided into two kinds: road mobile source and non-road mobile source. The road mobile source includes seven types of vehicles, of which the activity level data from the Changchun 2016 motor vehicle Holdings, through the 2003-2016 registered motor vehicles to determine the number of vehicle emission standards and then the emission factor. Mobile machinery of non-road mobile sources including construction machinery, agricultural machinery, railway diesel locomotives and civil aviation aircraft. Construction machinery and railway internal combustion engine fuel consumption comes from the energy balance table related data, civil aircraft take-off and landing cycle number is gained through the landing and take-off converting [10], the determination of emission coefficient is similar as road mobile sources. The amount of agricultural machinery was sorted out, the ratio of agricultural machinery in each discharging stage was estimated, and the $\mathrm{PM}_{2.5}$ emissions were finally obtained by combining the relevant emission coefficient data from the technical guide of the non-road mobile source air emission inventory.

In the process of estimating emissions from Changchun biomass combustion sources, this paper considers only the household biomass stoves and biomass open combustion, of which biomass stoves emissions in the second classification of the estimate (including straw and firewood), biomass open combustion only in the straw burning in the third classification of the category on the estimate (including corn, wheat, rice and other stalks). Activity level data obtained through the review of the Changchun Statistical Yearbook (2016), and other parameters of grass tristable, burning rate, etc. obtained through the collation of the literature, of which the proportion of straw open burning is difficult to determine, through the reference to the Jilin Province, the average burning ratio of $14.7 \%$ [11], and combined with Changchun the actual situation, finally take $10 \%$.

Dust source contains a total of four categories, respectively, for soil dust, road dust, construction dust and yard dust. In the estimation process of $\mathrm{PM}_{2.5}$ emissions of soil dust, only two types of land use are considered. $\mathrm{PM}_{2.5}$ emission factor of soil dust source is determined by parameters such as annual precipitation, average temperature, average wind speed, soil wind erosion index, and other parameters is from reference data in the guide. Road dust estimates only take the impact of road paving into account, combined with data access and field visits and relevant departments, reference to the dust source particulate emissions inventory preparation technology guide to obtain final emissions. In the process of estimating the dust and dust in the construction, the activity level data are obtained combination with the statistic data and the field survey and the Statistical Yearbook, while the remaining parameters refer to the relevant part of the preparation technical guide of the Particulate matter emission inventory of the dust source and the conversion.

In the process of establishing the emission inventory of sulfur dioxide source, referring to the basic data of the relevant departments, and combining with the classification characteristics of the current Statistical Yearbook activity data and Changchun the actual industry characteristics, this paper analyzes and collates the coal-burning quantity in various industries of Changchun, according to the electric power, heating, industry, civil and traffic of the five major industries to carry out material balance algorithm from the bottom up to gain the Changchun 2016 sulfur dioxide emissions inventory [12].

In the process of establishing the NOx emission inventory, the activity level data is from the Changchun Energy balance table statistic data (2016), the nitrogen oxide removal rate is obtained by analyzing domestic and foreign research report. Referring related literature emission factor data, based on the detailed activity level data, the bottom-up approach is used to estimate the NOx emission inventory in Changchun in 2016.

Monte Carlo method is a combination of probability and statistical theory of an algorithm. Using Monte Carlo method to quantitatively analyze the uncertainty of emission inventory, first, the probability density function of the input parameter is determined, and then probability density function is used to calculate the emission results by using these random values, the results are statistically analyzed, finally the output of emission inventory is the uncertainty result [13]. 


\section{Results and Discussions}

\subsection{Fine Particulate Matter Source Emission Inventory}

The results of Changchun fine particulate matter source emission inventory in Changchun in 2016 were obtained by estimating and analyzing, as shown in table 1 below.

Table 1. $P M_{2.5}$ source Emissions inventory in Changchun (unit: $t$ ).

\begin{tabular}{llll}
\hline source category & Industry & Emissions by industry & Emissions by sources \\
\hline \multirow{2}{*}{ fixed combustion source } & Power & 7119.46 & 17720.87 \\
& Heating & 3835.22 & \\
& Industry & 5940.42 & 825.77 \\
& Civil & 109.52 & \\
process source, & Steel & 16062.27 & 16309.73 \\
& Building materials & 101.13 & \\
mobile source & Petrochemical & 36.81 & 16319.03 \\
& Waste treatment & 13973.61 & 11062.66 \\
biomass burning source & Road & 2345.42 & \\
& Non-road & 596.24 & 9574.16 \\
dust source & Household Biomass Boilers & 10466.42 & \\
& Biomass Open combustion & 0.44 & 70986.45 \\
\hline
\end{tabular}

The results show that all kinds of source emissions are fixed combustion source, mobile source, process source, biomass burning source and dust source in order from large to small.

The contribution of fixed combustion sources is in the first place, and the emissions have declined significantly compared with previous years, but the contribution of electricity, heating and industry emissions cannot be neglected. This is due to the steady decline in Changchun industrial production in recent years, especially the automobile production industry, while Changchun take remedial work to the coal-fired boilers.

The contribution of mobile source and process source emissions is similar, in which the contribution of the two-level emission sources in the process source is analyzed, and it can be seen that the emission contributions of the building materials industry are outstanding, which originates from the large number of Changchun cars and the weak trend of Changchun construction industry in recent years.

Biomass combustion emissions play a key role in the contribution of sources, which is mainly attributed to the seasonal obvious straw incineration. Although in recent years Changchun has been increased management whose efforts have also been effective, because of its stubborn and far-reaching impact it should be paid attention to. It is suggested that the energy processing enterprises with straw as raw materials should be subsidized, and the related enterprises should be encouraged to collect the straw from farmers for compensation [14].

The contribution of the dust source is the lowest, but it is higher than the previous years, which mainly originates from the Changchun construction industry and the improvement of urban construction work.
$\mathrm{PM}_{2.5}$ distribution of various types of emission sources in Changchun is shown in Figure 1 below.

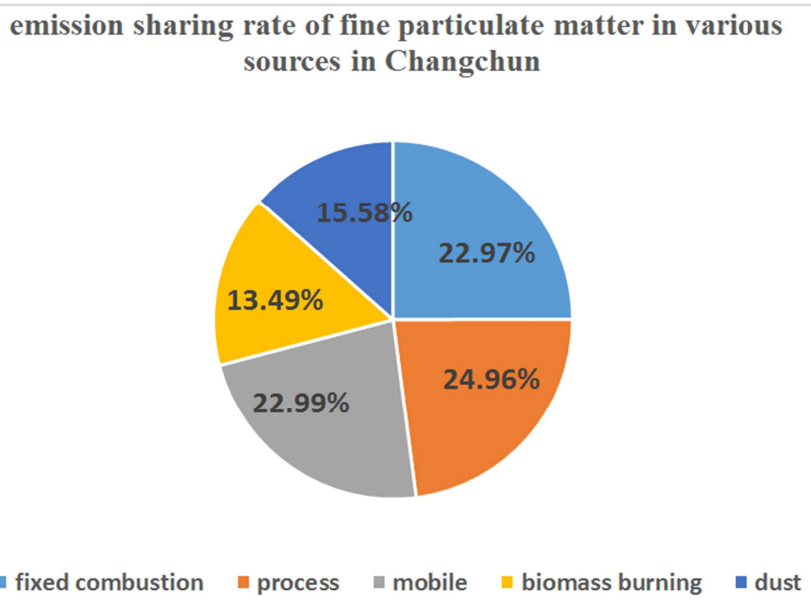

Figure 1. Fine particulate matter source emission ratio in Changchun.

It is shown from Figure 1 that fixed combustion source is the largest source of emission of Changchun $\mathrm{PM}_{2.5}$, accounting for $24.96 \%$ of total $\mathrm{PM}_{2.5}$ emissions, which is related to coal consumption and energy fuel quality in related industries. The emission sharing rate of the mobile source and the process source was relatively large, $22.99 \%$ and $22.97 \%$ respectively. The emission sharing ratio of biomass combustion source and dust source is relatively small, and the emission ratio is $15.58 \%$ and $13.49 \%$ respectively.

According to the uncertainty analysis of Changchun fine particulate source emission inventory by Monte Carlo method, 
the uncertainty range of emission sources is relatively small, the uncertainty range of biomass combustion source emission is- $23.2 \% \sim 23.2 \%$, and the uncertainty range of fixed combustion source is-9.4\% 9.4\%, the uncertainty range of road mobile source in mobile source is- $10.7 \% \sim 10.7 \%$, the uncertainty range of non-road mobile source is- $12.0 \% \sim 12.0 \%$, the uncertainty range of process source is-8.4\% 8.4\%, the uncertainty range of dust source is- $14.7 \% \sim 14.7 \%$. This shows that the inventory results are more credible.

\subsection{Emission Inventory of Sulfur Dioxide Sources}

The results of 2016 emission inventory of sulfur dioxide sources in Changchun are obtained by estimating and analyzing, as shown in table 2 below.

Table 2. $\mathrm{SO}_{2}$ source emissions inventory in Changchun (unit: $t$ ).

\begin{tabular}{lll}
\hline Industry category & Coal quantity & Emissions \\
\hline Industry & 306.35 & 17645.76 \\
Heating & 323.37 & 6208.70 \\
Electric power & 600.28 & 23050.75 \\
Civil & 43.38 & 4372.70 \\
Traffic & 40.43 & 905.63 \\
total & & 52183.55 \\
\hline
\end{tabular}

The results show that the emissions from large to small in each industry are electric electric power, industry, heating, civil and traffic in turn. From table 2, Changchun energy structure is mainly based on coal, consumption in the first place is the electric power industry, its corresponding $\mathrm{SO}_{2}$ contributions accounted for the largest, followed by industry and heating industry, the two coal consumption and $\mathrm{SO}_{2}$ emissions are relatively large, the contribution of the lowest emission value is the traffic industry.

In summary, the main source of $\mathrm{SO}_{2}$ is the emissions from coal combustion process in industrial, electric electric power and heating boilers, as well as the emission sources of motor vehicles, waste incineration and straw burning in the civil and traffic.

$\mathrm{SO}_{2}$ distribution of emission sources in various industries in Changchun is shown in Figure 2 below.

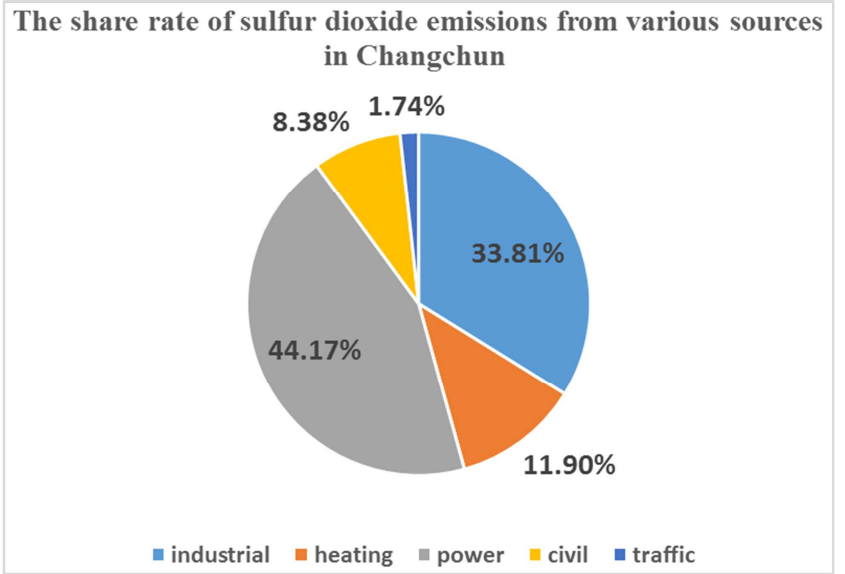

Figure 2. Emission ratio of sulfur dioxide source in Changchun.

From Figure 2, the main source of coal consumption caused a large amount of sulfur dioxide emissions, of which the electric power industry is the largest contributor to the total emissions of the share rate of $44.17 \%$, while the industry and the heating emission contribution rate is relatively large, respectively accounted for $33.81 \%$ and $11.9 \%$, The emission share of the traffic industry is $1.74 \%$, but it is still not negligible.

The uncertainty analysis of Changchun sulfur dioxide emission inventory by Monte Carlo method shows that the uncertainty range of emission sources is small, among which the uncertainty range of industrial emission source is- $15.6 \% \sim 15.6 \%$, and the uncertainty range of heat source is- $11.4 \% \sim 11.4 \%$. The uncertainty range of electric power source is-12.2\% 12.2\%, the uncertainty range of living emission source is $-17.8 \% \sim 17.8 \%$, and the uncertainty range of traffic emission source is- $18.0 \% \sim 18.0 \%$. This shows that the inventory results are more credible.

\subsection{Emission Inventory of NOx Sources}

The results of 2016 NOx emission inventory in Changchun are obtained by estimating and analyzing, as shown in table 3 below.

Table 3. NOx Emissions inventory in Changchun (unit: million t).

\begin{tabular}{|c|c|c|c|c|c|c|c|c|c|c|}
\hline Industry category & Coal & Crude oil & Gasoline & Kerosene & diesel oil & Fuel oil & Refinery dry gas & Gas & Coal gas & Emission \\
\hline Heating & 323.37 & & 0.06 & & & & & 0.27 & & 0.91 \\
\hline Electric power & 600.28 & & & & 0.16 & 0.01 & & 0.13 & & 2.90 \\
\hline Industry & 306.35 & 0.59 & 64.79 & 0.01 & 38.69 & 0.13 & 0.02 & 54 & & 2.29 \\
\hline Traffic & 40.43 & & 38.97 & & 108.28 & & & 51.87 & & 6.14 \\
\hline Civil & 43.38 & & 24.3 & 0.07 & 39.37 & & & 9.31 & 1.03 & 0.91 \\
\hline total & & & & & & & & & & 13.15 \\
\hline
\end{tabular}

The results show that the Changchun energy structure includes some oil and combustible gas besides the main coal resources. Emissions from all sectors from large to small in turn for traffic, electric power, industry, heating and civil industries. The largest source of pollution emissions in the traffic industry, diesel consumption is significantly higher, which stems from the large-scale use of trucks and high-frequency transport [15]. The consumption of coal in the energy structure of heating, electric power and industry is outstanding, and the use of coal-fired boilers in the three industries is the main cause of $\mathrm{SO}_{2}$ and $\mathrm{NO}_{\mathrm{x}}$ emission in the air pollutants, combined with table 2 .

The distribution of $\mathrm{NO}_{\mathrm{x}}$ emission sources in various industries of Changchun is shown in Figure 3 below. 


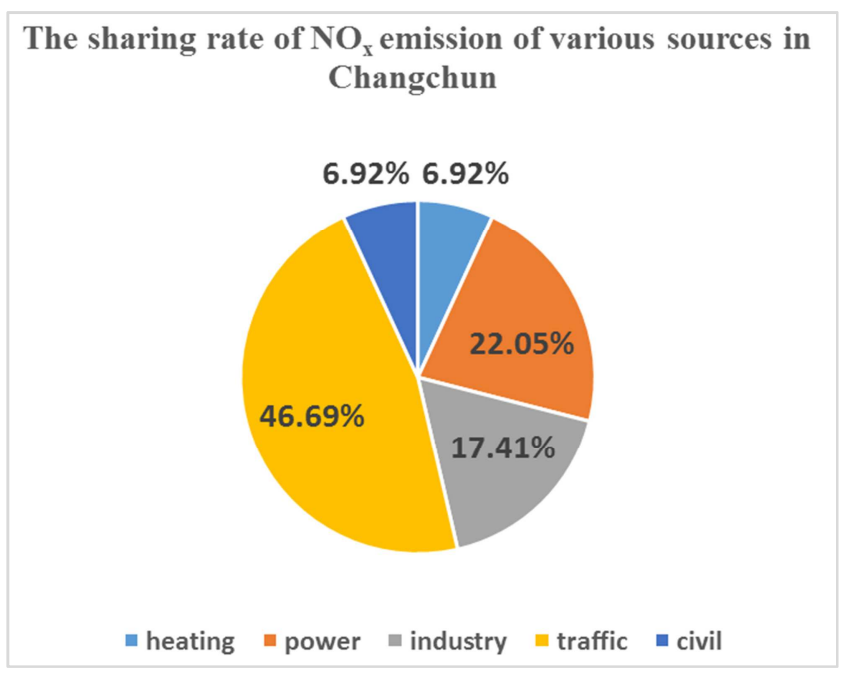

Figure 3. The emission ratio of $N O_{x}$ sources in Changchun city.

Figure 3 shows that the traffic industry is the first major source of nitrogen oxides, mainly from the heavy diesel goods vehicles and petrol minibus emissions, accounting for $46.69 \%$ of the total emissions, followed by the electric power and industry, coal-fired boilers attributed to a large number of coal burning, both accounted for the total emissions of $39.46 \%$. The lower rate of emission sharing is the civil and heating industry, accounting for $6.92 \%$, it is noteworthy that in the same type of energy composition, the air pollution in the heating industry, $\mathrm{NO}_{\mathrm{x}}$ emissions are far less than the emissions of sulfur dioxide.

By using Monte Carlo method to analyze the uncertainty of the NOx emission inventory in Changchun, it is shown that the uncertainty range of the sources is relatively small, among which the uncertainty range of the source of heat supply is- $20.3 \% \sim 20.3 \%$, and the uncertainty range of the electric power source is-22.7\% 22.7\%. The uncertainty range of industrial emission source is- $18.9 \% \sim 18.9 \%$, the uncertainty range of traffic emission source is $-17.1 \% \sim 17.1 \%$, and the uncertainty range of source of civil is-14.5\% 14.5\%. The inventory results are quite believable.

\section{Conclusions}

In 2016, the total emission of fine particulate matter in Changchun is 70986.45t, and the emissions of each sub-class source are fixed combustion source, mobile source, process source, biomass burning source and dust source respectively, which accounted for the ratio $24.96 \%, 22.99 \%, 22.97 \%$, $15.58 \%$ and $13.49 \%$. In terms of emission sharing, the largest contributor to $\mathrm{PM}_{2.5}$ emissions comes from the use of fixed burning sources of coal, the main emissions sector are electric power, industry and heating.

Coal-based energy consumption structure not only contributes significantly to the emission of one fine particulate matter, but also emits a large number of two fine particulate precursor materials, such as sulfur dioxide, nitrogen oxides. The total sulfur dioxide emission in Changchun in 2016 is 52183.55t, and the total $\mathrm{NO}_{\mathrm{x}}$ emission is 13.15 million tons. In the inventory of $\mathrm{SO}_{2}$ emission sources, the emissions from the various industries are in the order of electric power, industry, heating, civil and traffic, respectively, accounting for the ratio of $44.17 \%, 33.81 \%, 11.90 \%, 8.38 \%$ and $1.74 \%$. The large amount of coal consumption and high motor vehicle ownership are the main contributing sources of $\mathrm{SO}_{2}$ emissions. In the inventory of $\mathrm{NO}_{\mathrm{x}}$ emission sources, the emissions from large to small in turn are traffic, electric power, industry, heating and civil, respectively accounted for $46.69 \%, 22.05 \%$, $17.41 \%, 6.92 \%$ and $6.92 \%$. In the inventory of $\mathrm{NO}_{\mathrm{x}}$ emission sources, the first major contributor traffic industry is mainly attributed to heavy diesel trains and petrol passenger cars, followed by the electric power and industry mainly from burning coal-fired boilers, which accounted for $39.46 \%$ of total emissions.

The uncertainty of the emission inventory of fine particulate matter, sulfur dioxide and dioxide source was analyzed by using Monte Carlo, the results showed that the uncertainty range was small and the inventory results were quite credible.

\section{References}

[1] Wang Peng, Ying Qi, Zhang Hongliang, Hu Jianlin, et al. Source apportionment of secondary organic aerosol in China using a regional source-oriented chemical transport model and two emission inventories [J]. Environmental Pollution, 2018, 237: 756-766.

[2] Shuhan Liu, Shenbing Hua, Kun Wang, Peipei Qiu, et al. Spatial-temporal variation characteristics of air pollution in Henan of China: Localized emission inventory, WRF/Chem simulations and potential source contribution analysis [J]. Science of the Total Environment, 2018, 624: 396-406.

[3] Fu X, Wang S X, Zhao B, et al. Emission inventory of primary pollutants and chemical speciation in 2010 for the Yangtze River Delta region, China [J]. Atmospheric Environment, 2013, 70: 39-50.

[4] Ming, L., Jin, L., Li, J., Fu, P., Yang, W., Liu, D., Zhang, G., Wang, Z., Li, X. $\mathrm{PM}_{2.5}$ in the Yangtze River Delta, China: Chemical compositions, seasonal variations, and regional pollution events [J]. Environ Pollut, 2017, 223, 200-212.

[5] Wang, J., Xie, X., Fang, C. Temporal and Spatial Distribution Characteristics of Atmospheric Particulate Matter $\left(\mathrm{PM}_{10}\right.$ and $\mathrm{PM}_{2.5}$ ) in Changchun and Analysis of Its Influencing Factors [J]. Atmos, 2019, 10 (11).

[6] Shen, F., Zhang, L., Jiang, L., Tang, M., Gai, X., Chen, M., Ge, $\mathrm{X}$. Temporal variations of six ambient criteria air pollutants from 2015 to 2018, their spatial distributions, health risks and relationships with socioeconomic factors during 2018 in China [J]. Environ Int, 2020, 137, 105556.

[7] Yao, L., Yang, L., Yuan, Q., Yan, C., Dong, C., Meng, C., Sui, X., Yang, F., Lu, Y., Wang, W. Sources apportionment of $\mathrm{PM}_{2.5}$ in a background site in the North China Plain [J]. Sci. Total Environ., 2016, 541.

[8] Alexis Laurent, Michael Z. Hauschild. Impacts of NMVOC emissions on human health in European countries for 2000 2010: Use of sector-specific substance profiles [J]. Atmospheric Environment, 2014, 85: 247-255. 
[9] Jiandong Li, Wei-Chyung Wang; Hong Liao, Wenyuan Chang. Past and future direct radiative forcing of nitrate aerosol in East Asia [J]. Theoretical and Applied Climatology, 2015, 121 (3): 44-458

[10] Jiamin Ou, Junyu Zheng, Rongrong Li, et al. Speciated OVOC and VOC emission inventories and their implications for reactivity-based ozone control strategy in the Pearl River Delta region, China [J]. Science of the Total Environment, 2015, 530: 393-402.

[11] Shuangqi Zhang, Mengsi Deng, Ming Shan, et al. Study on the energy and environmental impacts of substituting molded straw fuels for heating coal in rural areas of northern China based on the amount of straw open burning [J]. Journal of Agro-Environment Science, 2017, 36 (12): 2506-2514.
[12] Chang J, Ren Y, Shi Y, et al. An inventory of biogenic volatile organic compounds for a subtropical urban-rural complex [J]. Atmospheric Environment, 2012, 56: 115-123.

[13] Yanci Liang, Handong Liang, Shuquan Zhu. Mercury emission from coal seam fire at Wuda, Inner Mongolia, China [J]. Atmospheric Environment, 2014, 83: 176-184.

[14] Wenyuan Chang, Hong Liao, Jinyuan Xin, et al. Uncertainties in anthropogenic aerosol concentrations and direct radiative forcing induced by emission inventories in eastern China [J]. Atmospheric Research, 2015, 166 (1): 129-140.

[15] Lili Wang, Jinyuan Xin, Xingru Li, Yuesi Wang. The variability of biomass burning and its influence on regional aerosol properties during the wheat harvest season in North China [J]. Atmospheric Research, 2015, 157: 153-163. 